\title{
A Polystyrene-Water Calorimeter
}

\author{
Steve R. Domen \\ National Bureau of Standards, Washington, DC 20234
}

Accepted: July 15, 1983

\begin{abstract}
The paper describes a new type of calorimeter that can be quickly put into operation for determining absorbed dose at a point in polystyrene. It also describes a unique method of decreasing drifts in electrical signals caused by temperature gradients. Two calibrated thermistors were placed close together between sandwiched polystyrene discs that were immersed in water. The assembly was irradiated with gamma rays from a cobalt- 60 source. The dose rate was about $14 \mathrm{mGy} / \mathrm{s}$ and exposure times were about $100 \mathrm{~s}$. The standard deviation for a daily set of measurements was about $0.7 \%$. A zero heat defect for polystyrene was assumed. A calculation converted the measurements to absorbed dose in water. The dose in water determined in this way, and with a graphite calorimeter, is $3-4 \%$ lower than that measured in an all-water calorimeter previously reported. Drifts in electrical signals are eliminated by a resistance-capacitance circuit placed across a Wheatstone bridge. The rate of potential change across the bridge (caused by the circuit) is adjusted to have an opposite effect to the drifts in electrical signals produced by temperature gradients within the calorimeter. The method can be applied to other calorimeters.
\end{abstract}

Key words: absorbed dose; calorimeter; heat defect; polystyrene; temperature drifts; thermistor; water.

\section{Introduction}

One purpose of this paper is to report on an investigation of a calorimeter for measuring absorbed dose $^{1}$ at a point in polystyrene and converting the results to also give absorbed dose in water. Another purpose is to describe a method of balancing drifts in electrical signals caused by temperature gradients. In general, the method can be applied to other calorimeters.

The calorimeter and the method of drift balance have been briefly described in previous publications $[1,2] .^{2} \quad$ In the present paper, the calorimeter (particularly) is described in detail.

Because the standard absorbing material is water [3], recent investigative studies of a calorimeter for

About the Author: Steve R. Domen is a physicist in NBS' Radiation Physics Division.

\footnotetext{
${ }^{1}$ Absorbed dose is the mean energy per unit mass imparted to matter by ionizing radiation. The SI unit of absorbed dose is the gray (symbol Gy). $1 \mathrm{~Gy}=1 \mathrm{~J} / \mathrm{kg}$ (=100 rad).

${ }^{2}$ Figures in brackets indicate literature references at the end of this paper.
}

measuring absorbed dose at a point in water were undertaken and reported [4,5]. It was pointed out [5] that the first major effort in the development of this type of calorimeter (in overcoming the physical problems of accurately and efficiently measuring a temperature rise at a point in water) was successfulbut that the second major effort still remained, that is, to determine the existence of and corrections for heat defects in irradiated water (heat defect is the energy absorbed or released in induced radiation chemical reactions, being positive or negative depending, respectively, on whether an endothermic or exothermic reaction takes place). Under cobalt-60 irradiation, the apparently measured absorbed dose rate in distilled water is $3.5 \%$ higher [5] than results obtained with a graphite calorimeter [6], the results being converted to apply to water [7]. Nearly the same result, $3.8 \%$ (derived from comparisons with ionization measurements), was reported [8] as a result of measurements made in a copy of the water calorimeter irradiated with cobalt-60.gamma rays and with photon beams up to a maximum energy of 25 $\mathrm{MeV}$; but for the case with electrons from 13 to 20 $\mathrm{MeV}$, the results with the water calorimeter were $1 \%$ lower than those derived from ionization measure- 
ments. This lower result does not appear to be in agreement with measurements in another copy of the calorimeter irradiated with 17 and $22 \mathrm{MeV}$ electrons [9], nor with what would be expected from theoretical calculations [10,11]. Reference [11] indicates that calo. rimetric results should be the same for photons as well as for electrons, assuming that the initial conditions of the water are effectively the same.

Comparison of results with other types of calorimeters would aid in the possible realization of an accurate and efficient instrument for use under widely different irradiation conditions. Such calorimeters should be constructed of materials having absorption properties close to that of water and having a negligible or known heat defect. Polystyrene is such a possible material. By using the techniques described in this paper, other materials can be used to compare their heat defects as a function of accumulated doseto investigate them for potential calorimetric use.

Reported results [12] indicate a $0.0 \pm 0.8 \%$ heat defect in a polystyrene sample irradiated with cobalt60 gamma rays, after a pre-irradiation of about $2 \mathrm{kGy}$. Within experimental error, no heat defect was observed with fast neutrons [13]. Other reported results [14] indicate that a polystyrene sample (from a different manufacturer) irradiated with $30-\mathrm{kV}$ x-rays gave only borderline evidence of a heat defect, $(0.67 \pm 0.94) \%$ standard deviation, a constant result as a function of accumulated absorbed dose. A heat defect of $0.1 \%$ was reported for polystyrene irradiated with $1.7 \mathrm{MeV}$ protons ([3], p. 14). Although these are limited irradiation conditions, the results suggested the construction and investigation of an absorbed dose calorimeter in which measurements are made directly in polystyrene and the comparison of this calorimeter with the water and graphite calorimeters under a wide range of conditions.

The present paper describes and reports results of investigations with a polystyrene-water calorimeter irradiated with gamma rays from a cobalt- 60 source. This combination of solid and liquid materials makes possible an efficient instrument that can be brought quickly into operation and balanced (in contrast to one with a large solid polystyrene cylinder and no means of controlling temperature drifts [15]). Advantage is taken of the mobility of water in quickly bringing it and a relatively thin polystyrene disc close to a uniform operating temperature.

Rapid control of objectionably large drifts (caused, for example, by small remaining temperature differences between the discs and water, or by successive runs with collimated beams of low-energy electrons) is a vital feature that a calorimeter must have to encourage its construction and use. In the water calorimeter previously reported, the drifts were essentially instantly controlled by making a small change in electrical power dissipated in the water [5]. In the presently described calorimeter, the drifts are also rapidly decreased by changing the internal temperature gradients in addition to applying another simple technique. This technique consists of merely changing a charging potential applied to a resistancecapacitance (RC) circuit placed across a Wheatstone bridge, to produce a changing potential across the bridge that has an effect opposite to that caused by remaining small temperature gradients.

This paper describes the new features and operation of the polystyrene-water calorimeter in detail. However, many details are not described or are only briefly described because the only physical difference between the present calorimeter and the water calorimeter is the detector that is used. Construction features, the bridge circuit, calorimeter setup, thermistor sensitivity measurements, and corrections for thermistor power dissipations have been detailed [5]. The present paper, too, is written in detail to aid those in particular who may want to construct the calorimeter and understand its design and behavior.

\section{Measurement Theory}

Advantage was taken of the low thermal diffusivity of polystyrene and water, which retard a temperature change at a point of measurement. Two bead thermistors were positioned close together between sandwiched polystyrene discs immersed in water. The thermistors formed opposite arms of a Wheatstone bridge to double the sensitivity in comparison with a one-thermistor bridge. ${ }^{3}$ The absorbed dose is

$$
D=(1 / 2)(\Delta R / R)\left(\bar{S}^{-1}\right)(c),
$$

where $D$ is the absorbed dose,

$(1 / 2)$ is the result of using two thermistors to measure a temperature,

$\Delta R / R$ is the fractional change in the Wheatstone bridge balancing resistor,

$\bar{S}$ is the mean fractional change in resistance of the thermistors per unit temperature rise, and $c$ is the specific heat capacity of polystyrene.

\footnotetext{
${ }^{3}$ The sensitivity could be doubled with a one-thermistor bridge, by doubling the potential applied across the bridge. This would quadruple the thermistor power dissipation. Reference [5] points out reasons for maintaining as low a power level as possible.
} 
If $c$ is in $\mathrm{J} /(\mathrm{g} \cdot \mathrm{K}), \mathrm{D}$ is in $\mathrm{kGy}$. The product $(1 / 2)(\Delta R / R)\left(\bar{S}^{-1}\right)$ is the temperature rise. The sensitivity, $\bar{S}$, was determined to an uncertainty of about $0.1 \%$.

The sensitivity is nominally $4 \%$ per degree and decreases by seven parts per thousand per degree increase at room temperature. The value of $c$ increases by four parts per thousand per degree at room temperature. Calculated changes in $\bar{S}$ and $c$ were determined by use of a probe mounted inside the calorimeter and connected to an instrument that displayed temperature with a resolution of $0,01 \mathrm{~K}$.

The value of $c$ used in this investigation, at an operating temperature of $22.5^{\circ} \mathrm{C}$, was $1.203 \mathrm{~J} /(\mathrm{g} \cdot \mathrm{K})$. This value was calculated from an equation [16]:

$$
\begin{array}{r}
c=(104.15)^{-1}\left(7.7551 \cdot 10^{5} T^{-2}+0.53447 T-41.58\right) \\
\mathrm{J} /(\mathrm{g} \cdot \mathrm{K}),
\end{array}
$$

where $T$ is the absolute temperature. One mole of polystyrene $=104.15 \mathrm{~g}$.

Equation (2) was fitted to results of specific heat capacity measurements (of various samples of amorphous polystyrene which had a density of 1.05 $\mathrm{g} / \mathrm{cm}^{3}$ ) determined by various investigators, from 200 $\mathrm{K}$ to $360 \mathrm{~K}$. The reported rms deviation is $0.5 \%$. Only selective results were used which were judged to meet satisfactory standards based on experimental technique, error limits, and accuracy of representation of the data.

Although a calculated value appears to be a reasonable result to use in this investigation, attempts are being made to determine the specific heat of samples (from which the detector was made) to an accuracy and precision within a few tenths of $1 \%$. Any further results or changes will be reported in a future publication.

\section{The Calorimeter}

Figure 1 shows some features of the calorimeter. Two $0.25 \mathrm{~mm}$ diameter bead thermistors are embedded near the central plane of two sandwiched discs of clear polystyrene. The central plane is near a $5 / \mathrm{cm}^{2}$ depth in once-distilled water that is partially electrically conductive. The discs are fastened to three acrylic rods secured to the bottom of a $30 \mathrm{~cm}$ cube water container constructed of acrylic material (mounting the rods on a vertical wall, and providing an entrance window, permits measurements with

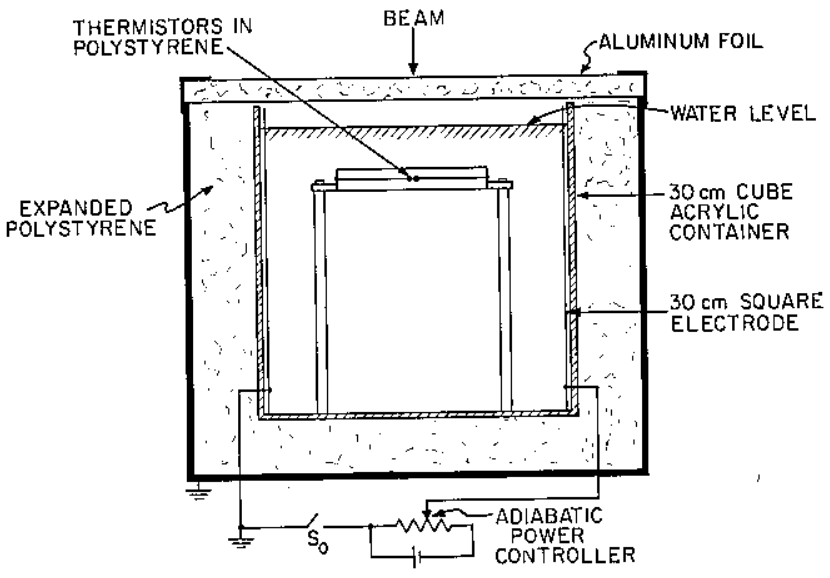

Figure 1-Essential features of the absorbed dose polystyrene-water calorimeter. The "adiabatic" power controller permits a potential to be applied across the electrodes so that in the vicinity of the discs the rate of temperature rise of the water, as a result of electrical power and beam irradiation, is as nearly as possible the same as that of the discs.

horizontal beams). Two electrodes (30 $\mathrm{cm}$ square stainless steel) for "adiabatic" operation are secured against opposite walls inside the container (in the water calorimeter they were the drift control electrodes [5]). The potential supply consists of a series-parallel arrangement of four $67.5 \mathrm{~V}$ drycell batteries which provide $135 \mathrm{~V}$ across a 10-turn $50-\mathrm{k} \Omega$ helipot. Closing switch $\mathrm{S}_{0}$ causes heating of the water. Measurements of potential across the electrodes and current through the stagnant water permit the determination of the rate of temperature rise of the entire water bath. The potential, $V$, is predetermined so that the rate of temperature rise of the water in the vicinity of the discs (as a result of electrical power and beam irradiation) produces as nearly as possible the same rate of temperature rise as do the polystyrene dises heated directly with broad beam irradiation. The electrical resistance of the water, usually in the range of 10-25 k $\Omega$, decreased during a daily set of measurements by about a factor of 2 . This increased the drifts but these could be reduced by making small changes in the adiabatic power controller.

The approximate potential across the electrodes is pre-determined as follows: The rate of temperature rise of the polystyrene can be calculated from the absorbed dose rate and the specific heat of polystyrene, or it can be determined from the measured rate of fractional resistance change of the known thermistor sensitivities. Considering that the specific heat of water is 3.5 times greater than that of polystyrene, and that the absorbed dose rate and heat 
defect in water are each approximately $3 \%$ greater, the rate of temperature rise in polystyrene irradiated with cobalt-60 gamma rays is approximately 3.3 times greater than that of water. The purpose of the electrical heating of the water is to make up the difference. Before an irradiation run (and particularly before the first run), an arbitrary potential, $V_{1}$, produced a current $I_{1}$. These measured values permitted a calculation of the electrical resistance of the water. The values $V_{1}$ and $I_{1}$ also permitted (as a first approximation) the calculation of the approximate potential, $V$, to accomplish adiabatic operation. Observations of the afterdrifts showed, however, that this value was too high by approximately $10 \%$. The reason for this is that the derivation of $V$ assumed a uniform current density throughout the water where in reality the current lines must necessarily be forced to flow around the discs. ${ }^{4}$ This causes a greater current density and thus a greater heating effect in the vicinity of their flat surfaces. A reasonably accurate formula was found to be

$$
V \cong 0.9 \sqrt{\dot{D} V_{1} / I_{1}},
$$

where $\dot{D}$ is the absorbed dose rate in $\mathrm{Gy} / \mathrm{min}$. In practice, observations of the drifts will indicate when the potential, $V$, needs to be adjusted.

\section{The Detector}

Figure 2 shows some details of the detector. Each thermistor, positioned $1 \mathrm{~mm}$ from the disc axis, is embedded. just underneath each inner surface. Each disc is $10 \mathrm{~mm}$ thick and $152 \mathrm{~mm}$ in diameter. Mainly to avoid damage to the wiring during assembly (and because of heat transfer considerations), the discs are separated by three $0.3 \mathrm{~mm}$ thick paper spacers $(6 \mathrm{~mm}$ in diameter) equally spaced near the disc circumference. Silicone rubber is applied around the discs' central plane to provide a watertight seal. The signal leads are connected to a waterproofed electrical socket fastened near the circumference of the lower disc. A small hole drilled along the axis of the socket permits enclosed air between the discs to vary with changes in atmospheric pressure.

It will be pointed out later that good mechanical and thermal anchoring (other than through air)

\footnotetext{
${ }^{4}$ If the chosen discs are electrically conductive (such as A-150 plastic [17] or graphite which has a reported heat defect near zero), then they must be electrically insulated from the water. Reference [18] reports an endothermic heat defect of about $4 \%$ for A.150 plastic irradiated under different conditions.
}

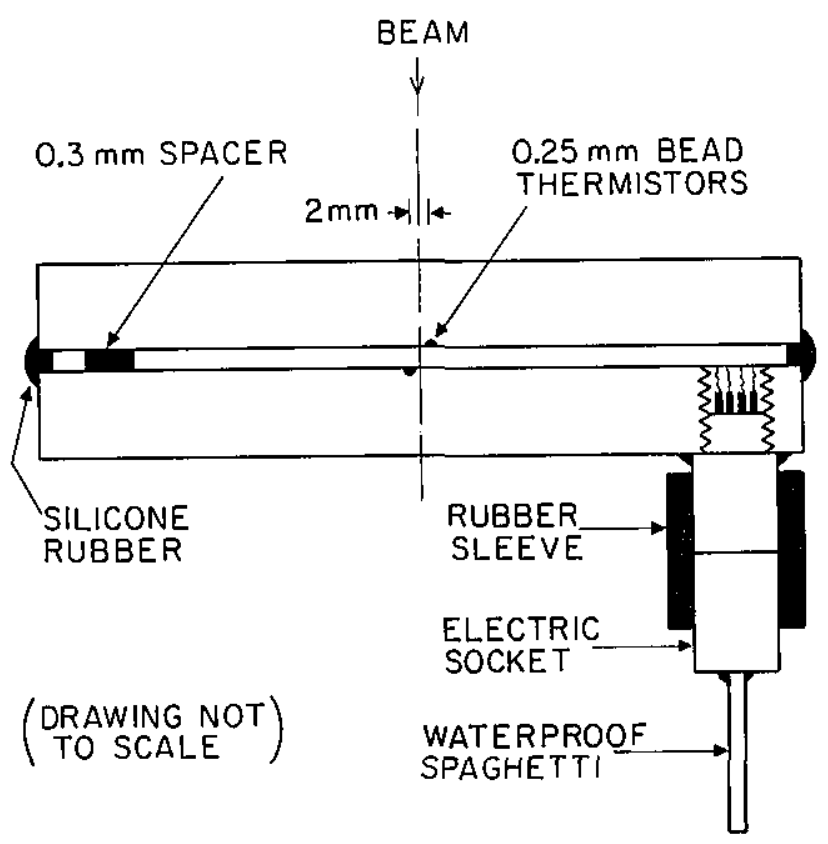

Figure 2-Constructional details of the detector. Each of the two polystyrene discs is $10 \mathrm{~mm}$ thick and $152 \mathrm{~mm}$ in diameter.

between the discs and thermistors (including the wires leading from them, for a length of at least $1 \mathrm{~cm}$ ) seems to result in important and desirable detector behaviors. Figure 3 shows the wiring configuration. A compass was used to scribe grooves slightly larger than the embedded wires. Each thermistor bead was commercially fused around two $25 \mu \mathrm{m}$ diameter wires (90\% platinum, $10 \%$ iridium) which are soldered to 25 $\mu \mathrm{m}$ diameter copper wires (the copper wires have a higher thermal conductivity by a factor of 12). The thermistors and the $1 \mathrm{~cm}$ lengths of Pt-Ir wires are totally embedded in epoxy resin. The copper wires are partially embedded in silicone rubber (which aided in the initial layout), and the remainder is entirely embedded in epoxy resin. The embedments were done with the aid of a microscope which also aided in removing minute amounts of embedding material outside the grooves. This precaution (and considering that their specific heat capacities are not largely different from that of polystyrene) made the irradiation thermal effects of those remaining materials negligible. The thermal effect of irradiating the small amounts of different materials (other than polystyrene) composing the wires and thermistors is negligible, $<0.01 \%$ within a few seconds after irradiation [5].

The purpose of the shown configuration (in preference to directing the wires directly to the socket) is to decrease possible conductive effects along the wires (caused by variations in radial dose rates) 


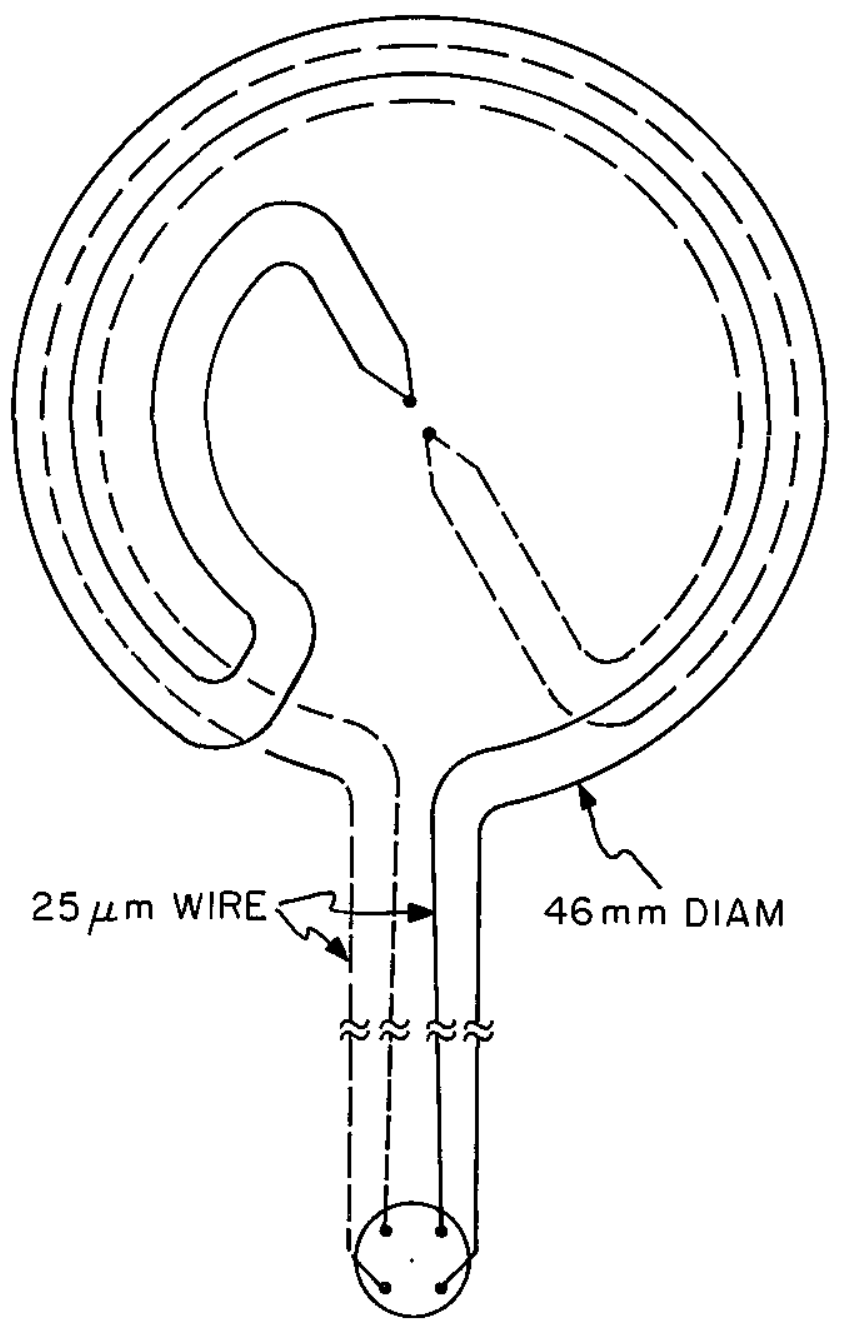

Figure 3-Wiring configuration of the detector.

which would tend to affect a temperature measurement. Because the longer lengths increase the resistance of the wires, their resistances are calculated to correct for their effects.

The measured density of the polystyrene discs was $1.050 \mathrm{~g} / \mathrm{cm}^{3}$. The discs' electron density (electrons per unit volume) is only $2 \%$ greater than that of water.

\section{The Wheatstone Bridge}

The upper part of figure 4 shows the simplified dc Wheatstone bridge circuit containing two thermistors. The circuit is used for determining both the fractional resistance change $(\Delta R / R)$ in the balancing resistor $(R)$ and the fractional change in thermistor resistance per degree temperature rise (S) of each thermistor, $\mathrm{C}$ and J-for use in eq (1). A selector switch permits measurements in the shown $(\mathrm{C}+\mathrm{J})$ mode, or in the $\mathrm{C}$

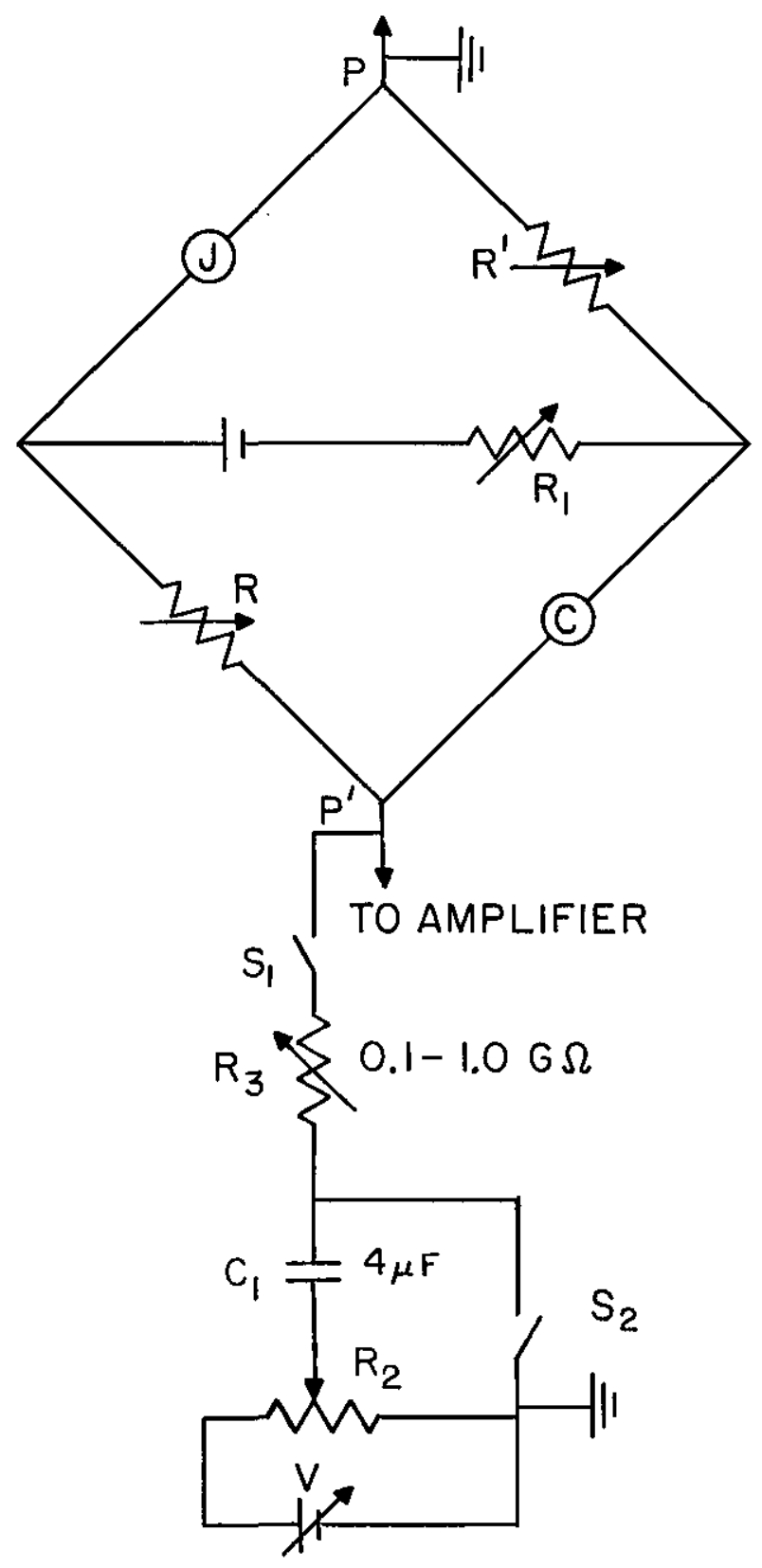

Figure 4-Wheatstone bridge circuit and signal drift balancer.

or $\mathbf{J}$ mode. Each arm of the bridge has a nominal resistance of $3 \mathrm{k} \Omega$. The dc output of the bridge was connected to a nanovolt null detector that consisted of a chopper, ac amplifier, and demodulator system followed by a dc amplifier.

\section{The Drift Balancer}

The new design feature is the RC-circuit, shown in the lower part of figure 4 . Switch $S_{1}$ permits the 
circuit to be either connected across or disconnected from the bridge and amplifier. The amplifier normally has a small in put resistance of about $300 \mathrm{k} \Omega$ compared to at least $0.1 \mathrm{G} \Omega$ of the RC-circuit. Its use and further details of the electrical signal drift balancer are described below.

\section{Thermistor Sensitivity Measurements}

The thermistor resistance value ( $r$ ) at a given absolute temperature $(T)$ is given by the well-known empirical expression:

$$
r=r_{0} \mathrm{e}^{\beta\left(1 / T-1 / T_{0}\right)}
$$

where $r_{0}$ is the resistance at temperature $T_{0}$ and $\beta$ is the "material constant."

The sensitivity of a thermistor $(S)$ is defined as $(1 / r)(\mathrm{d} r / \mathrm{d} T)$, which gives

$$
S=-\beta / T^{2} .
$$

Equation (4) can be reduced to linear form:

$$
y=\beta x+\theta,
$$

where $y=\ln r, x=1 / \mathrm{T}$, and $\theta=\ln r_{0}-\beta / T_{0}$, a constant. Least-squares fits of the data are applied to eq (6).

Resistance measurements were made in a temperature range of $16-28^{\circ} \mathrm{C}$, in steps of 2 degrees. A crystal thermc meter (1 $\mathrm{mK}$ resolution) measured the temperature of the surrounding agitated water. When necessary, the temperatures were maintained within several millikelvin by adding ice water or by momentarily supplying $400 \mathrm{~W}$ of electrical power to immersion heaters (not shown in fig. 1).

The relatively small thickness $(10 \mathrm{~mm})$ of each sandwiched disc results in a reasonably short time for the thermistors to reach their ultimate temperature change. This is illustrated in figure 5. It shows the result of calculations from the use of theoretical values tabulated $[19,20]$ combined with a thermal diffusivity of $12.4 \times 10^{-4} \mathrm{~cm}^{2} / \mathrm{s}$ determined from a table of recommended values for polystyrene [21], at the calorimeter operating temperature (for water it is $14.4 \times 10^{-4} \mathrm{~cm}^{2} / \mathrm{s}$ ).

Consider that the entire system is at initial temperature $T_{\mathrm{i}}$ and that the agitated water is suddenly raised (or lowered) in temperature to $T_{\mathrm{f}}$. The curve shows the amount of temperature change (in percent of the ultimate temperature change) of the thermistors as a function of time. At 26 and 39 minutes the thermistors theoretically reach, respectively, 99 and $99.9 \%$ of their total temperature change. (Figure 5

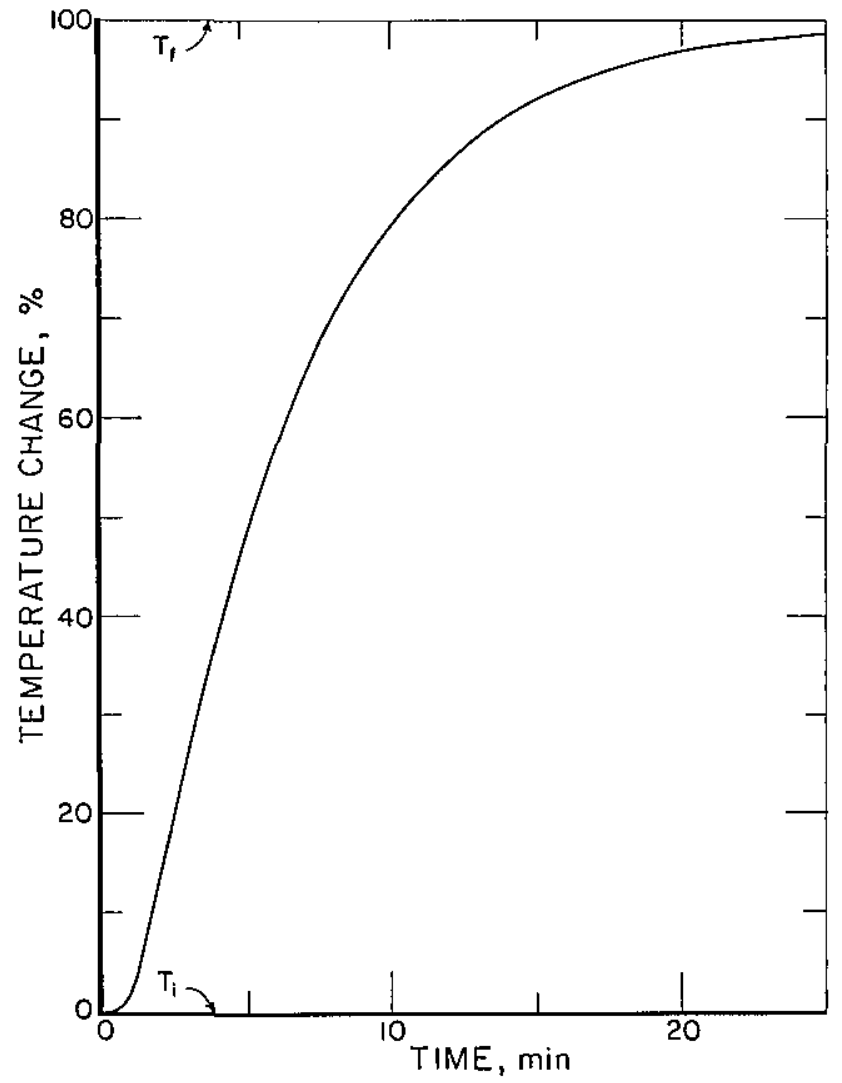

Figure 5-Temperature equilibration at the central plane of the sandwiched polystyrene discs, each $10 \mathrm{~mm}$ thick.

applies to any pair of sandwiched polystyrene dises each of thickness $t \mathrm{~cm}$, when the shown numerical values of the abscissas are multiplied by $\mathrm{t}^{2}$.) However, at $30-35 \mathrm{~min}$ (in practice) the bridge output indicated that further resistance (temperature) changes were insignificant. The resistances were then determined from the known resistance values of $R$ and $R^{\prime}$ and from measured potentials across each bridge arm.

The results are shown in table 1 . The first set of measurements was made before the calorimeter underwent radiation. Two months later a second set of measurements was made after the detector had received $1.33 \mathrm{kGy}$ of absorbed dose. The results show

Table 1. Measured values of the "material constant," $\beta$

\begin{tabular}{lcc}
\hline $\begin{array}{l}\text { Accumulated } \\
\text { dose } \\
(\mathrm{kGy})\end{array}$ & $\begin{array}{l}\beta_{\mathrm{C}} \\
(\mathrm{K})\end{array}$ & $\begin{array}{l}\beta_{\mathrm{J}} \\
(\mathrm{K})\end{array}$ \\
\hline 0 & 3134.1 & 3178.6 \\
1.33 & $\underline{3137.2}$ & $\underline{3177.6}$ \\
\hline
\end{tabular}


insignificant changes. A mean value, $\bar{\beta}$, of $3157 \mathrm{~K}$ was used for the $(C+J)$ mode indicated in figure 4 .

\section{Calorimeter Setup}

In order to compare results, the polystyrene-water calorimeter was irradiated under conditions essentially identical to those of the graphite and water calorimeters. Irradiations were made with the same cobalt-60 unit collimated to give the same-sized broad beam. Optical sighting and micrometer measurements were used to accurately position the central planes of the sensing units near $1 \mathrm{~m}$ from the source and at a mass depth near $5 \mathrm{~g} / \mathrm{cm}^{2}$.

\section{Drift Balance}

Reduction of temperature gradients which cause drifts first requires elimination of large drifts (after water is introduced in the calorimeter) and then reduction and stabilization of subsequent small drifts observed at high amplification.

The calorimeter was most stable when it was made uniform in temperature at the room temperature regulated near $22.5^{\circ} \mathrm{C}$. The introduced water was about 1 degree cooler. This caused cooling of the polystyrene discs during the calorimeter setup. The water was then agitated with a gas and raised to room temperature by use of the immersion heaters. The heaters were then turned off, but the agitation continued. The output of the Wheatstone bridge indicated the general thermistor response shown in figure 5. At about 30-35 minutes the agitation was turned off. Irradiation measurements were made when the water was stagnant (tests showed that this condition permitted much better reduction and control of drifts than when the water was agitated and raised in temperature during a measurement).

In theory, it would seem that prolonged agitation would result in insignificant temperature drifts. In practice, subsequent drifts observed at high amplification should not be expected to be zero, to remain constant, or to be small because they can change as a result of a number of internal and/or external causes. Significant drifts were usually observed after prolonged agitation. This could have been caused by the temperature of the incoming agitating gas and/or as a result of heat exchange with the outside of the container which may have resulted in a small temperature difference between the water and discs. As a result, significant cooling drift rates (at times) were observed even though theoretical calculations showed that a significant heating drift rate of $150 \mu \mathrm{K} / \mathrm{min}(0.18 \mathrm{~Gy} / \mathrm{min})$ would be present at the end of $40 \mathrm{~min}$ of agitation.

Some causes of the behavior of subsequent drifts result from imperfect "adiabatic" operation. Changes in drifts can also be caused by changes in temperature gradients that result from variations in axial and radial dose rates, effects which will increase as successive runs are made. Therefore, rapid reduction and control of drifts is a vital and time-saving operation.

The effect of non-adiabatic operation is illustrated by the recording shown in figure 6 . The small initial drift indicated near equilibrium conditions, switch $S_{1}$ open (fig. 4). A broad cobalt-60 beam was turned on for $90 \mathrm{~s}$, switch $S_{0}$ open (fig. 1). Figure 6 indicates that the polystyrene discs rose higher in temperature, $\Delta T_{\mathrm{p}}$, compared to the surrounding water that rose less in temperature, $\Delta T_{\mathrm{w}}$. This caused rapid and non-linear cooling after irradiation, as shown by the recording.

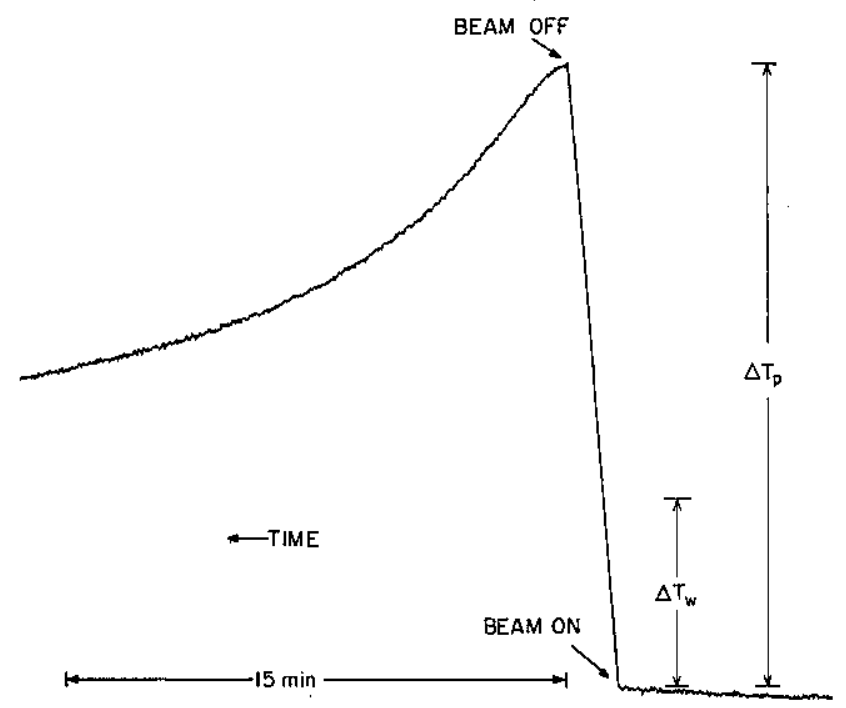

Figure 6-Recording of a non-adiabatic run of $90 \mathrm{~s}$ irradiation. The temperature rises of the polystyrene discs and surrounding water are indicated by $\Delta T_{\mathrm{p}}$ and $\Delta T_{\mathrm{w}}$, respectively.

Figure 7 illustrates the basic idea of rapidly decreasing and balancing drifts by use of the RC circuit shown in figure 4 . Consider switches $S_{1}$ and $S_{2}$ initially open. The 10 -turn, $10-\mathrm{k} \Omega$ potentiometer, $\mathbf{R}_{2}$, was adjusted to about mid-scale and then $S_{2}$ was momentarily closed across the $4-\mu \mathrm{F}$ polystyrene capacitor. The circuit was then connected to the bridge by closing $S_{1}$. Assuming that there are no temperature drifts, the bridge output signal will indicate a zero signal as illustrated by the baseline segment $\mathrm{OA}$ in figure 7. If $\mathrm{R}_{2}$ is adjusted to give signal $\mathrm{AB}$ or $\mathrm{AC}$, the signal will decay to the baseline at a 


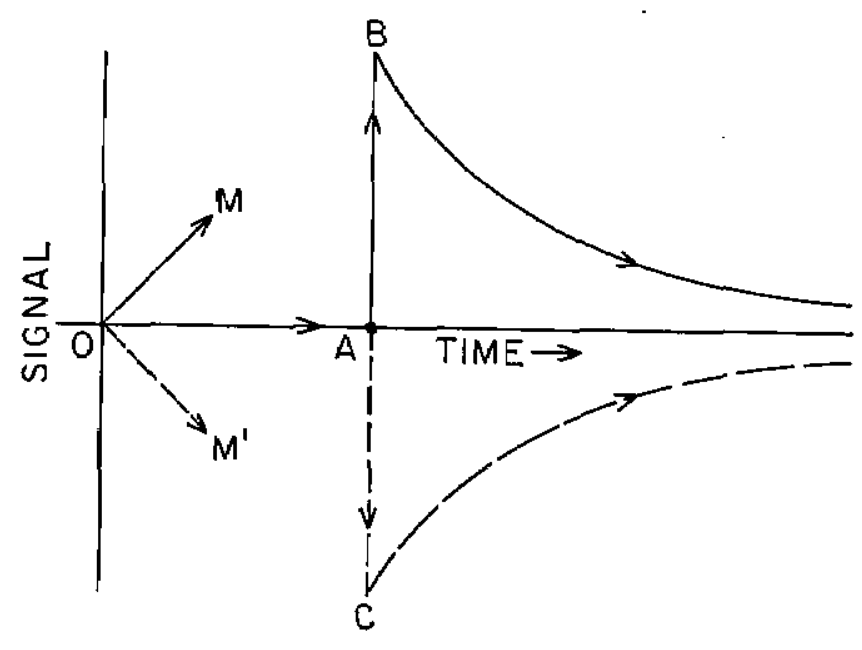

Figure 7-Illustration of the principle used in balancing drifts in electrical signals caused by temperature gradients within the calorimeter.

rate depending mainly on the value of $\mathrm{R}_{3} \mathrm{C}_{1}$. In this way, a changing external electrical signal was applied across input $\mathbf{P P}^{\prime}$ of the amplifier input (or output) to oppose a drift in electrical signal caused mainly by internal temperature gradients. For example, an increasing signal produced by a heating temperature drift in the general direction of OM (fig. 7) will be opposed by a decrease of the electrical signal AB. And a decreasing signal produced by a cooling temperature drift in the direction of $\mathrm{OM}^{\prime}$ will be opposed by a decay of the electrical signal $\mathrm{AC}$.

The RC circuit was adjustable to balance a large range of electrical signal drifts. The resistor $R_{3}$ was adjustable to give four resistance values from 0.1 to $1.0 \mathrm{G} \Omega$. This gave time constants of $7,13,33$, and 67 minutes. The potential $\dot{V}$ was adjustable in order to place from one to four 1.35 -volt mercury cells in series. The maximum electrical drift that could be produced at the amplifier input was equivalent to an absorbed dose rate drift near $7.6 \mathrm{~Gy} / \mathrm{min}$ in the $(\mathrm{C}+\mathrm{J})$ mode, when $4.5 \mu \mathrm{W}$ of electrical power was dissipated in each thermistor. However, during measurements only small adjustments were needed as will be illustrated below.

Although the RC circuit can greatly reduce observed drifts, it is always good practice to reduce internal temperature gradients as much as possible so that only a small and remaining drift needs to be balanced. This allows more linear drifts which lessen extrapolation errors when analyzing runs. This condition will also permit longer and more accurate irradiation runs, particularly when measuring low dose rates. A large drift observed over a small time at a reduced amplifier gain may appear to be linear; and although the RC circuit will oppose the large drift, the remaining drift might appear to have an objectionably large curvature, particularly when observed under measurement conditions that require a high ampliffer gain. Therefore, a way to improve this situation is mainly to decrease the internal temperature gradients.

Reduction of internal temperature gradients in the stagnant water was accomplished in a simple manner. Switch $\mathrm{S}_{1}$ was open. A heating drift generally meant that heat was conducted from the warmer surrounding water to the cooler polystyrene discs. This drift was reduced by momentary irradiation which raised the temperature of the discs at a rate nearly 3.3 times greater than the surrounding water (switch $S_{0}$ of fig. 1 remaining open). This procedure was repeated in steps until the drift was desirably small. Conversely, a cooling drift was reduced by momentarily closing switch $S_{0}$ (no beam irradiation), and the procedure was repeated until the drift was also desirably small. After each of these procedures, reasonably short periods of waiting were required to allow for approximate temperature equilibration between the discs and surrounding water. When the drifts are reduced to reasonably small values, further application of these procedures may result in an uneconomical use of time. At this point the RC-circuit can be put into use. Some delayed control of small drifts can be made during measurements by making required adjustments in the adiabatic power controller (fig. 1).

\section{Performance}

Figure 8 shows the performance of the calorimeter. Time increases from right to left. The initial upward drift shown was considered too large. This heating drift signaI was reduced by merely adjusting $R_{2}$ to cause the recorder pen to move in the direction of the

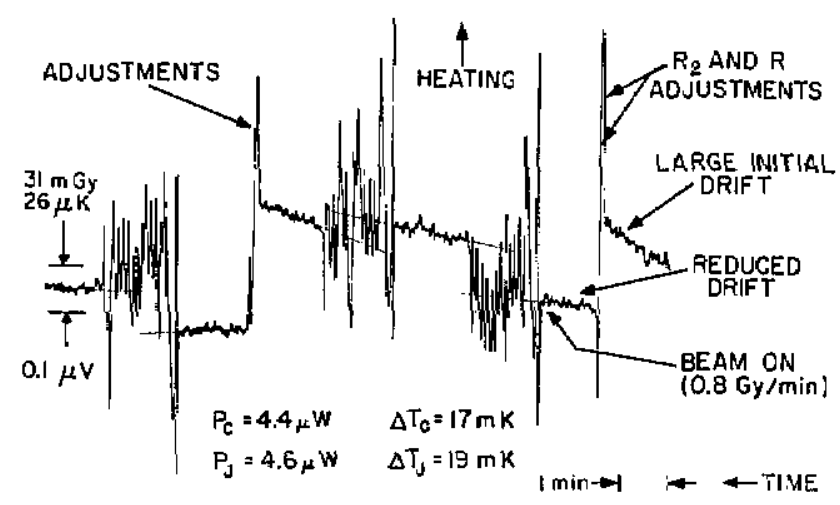

Figure 8-Recorder tracings illustrating quickly balanced electrical signal drifts, large signal-to-noise ratio, and the rapidity of measurements. 
drift (upward). ${ }^{5}$ Then an adjustment was made by changing the Wheatstone bridge balancing resistor, $\mathbf{R}$, causing the pen to move approximately to the chart mid-scale (the null position). The result shows a much reduced drift signal; and although it could easily have been reduced further, it was considered negligible compared to the beam response. Then switch $\mathbf{S}_{0}$ (fig. 1) was closed and the beam was immediately turned on. $R$ was adjusted around the null (mid-scale) until $S_{0}$ was opened and the beam turned off after $90 \mathrm{~s}$. The abrupt spikes shown are the result of this manual change in $R$. Two runs were made before further adjustments were made in $R_{2}$ and $R$.

The beam dose rate was near $0.8 \mathrm{~Gy} / \mathrm{min}$ which produced a $1.0 \mathrm{mK}$ temperature rise in $90 \mathrm{~s}$. This is small compared to the average $18 \mathrm{mK}$ temperature rise of the thermistors as a result of an average electrical power dissipation of $4.5 \mu \mathrm{W} .{ }^{6}$ The total pen deflection during a run was 41 times greater than the indicated distance for $31 \mathrm{mGy}$. The electrical noise was small.

Figure 8 illustrates control of only small temperature drift signals, up to $17 \mu \mathrm{K} / \mathrm{min}$. Tests (not shown) indicated that much larger temperature drifts were also reduced and balanced by the $\mathrm{RC}$ circuit. The simplicity of the circuit and its ease of use are desirable features for applying it to other calorimeters, in general. (A complicated circuit could be designed to reduce drifts during runs by generating feedback ramp signals predicted by curve fits to background drifts.)

Experience with the calorimeter has shown its utility. Positioning the empty calorimeter, filling it with water to an accurate depth, getting it into operation, and making 30 runs of $100 \mathrm{~s}$ duration for each irradiation required about 4 hours.

Insignificant temperature effects were caused in the thermistors as a result of adjusting $R_{2}$ in the drift balancer. In figure 8 , the first shown adjustment in $\mathbf{R}_{2}$ produced an initial potential change across $\mathbf{P P}^{\prime}$ (in fig. 4) of about $0.4 \mu \mathrm{V}$. This caused a power change of $15 \times 10^{-6} \mu \mathrm{W}$ in each thermistor. The temperature change was $(4.1)\left(15 \times 10^{-6}\right) \mathrm{mK}=0.06 \mu \mathrm{K}$. This is

\footnotetext{
${ }^{5}$ The effect of superimposing the exponentially decaying signals $\left(\mathbf{R}_{3} \mathrm{C}_{1}=13\right.$ minutes) on the linear drifts resulted in a theoretical error of $<0.01 \%$-for the runs shown in figure 8 .

${ }^{6}$ Within $3 \%$, each thermistor rose in temperature by $4.1 \mathrm{P} \mathrm{mK}$, where $P$ is the thermistor power dissipation in $\mu \mathrm{W}$. Tests showed that when either thermistor changed in temperature by $\delta \mathrm{T}$, as a result of a change in $P$, it produced a temperature change of 0.044 $\delta \mathrm{T}$ in the other thermistor-as determined by the rebalance of the Wheatstone bridge.
}

small compared to the noise level which can be estimated as an equivalent temperature change of several microkelvin by use of the illustrated temperature scale shown at the left in figure 8. Furthermore, about 95 percent of the additional 0.06 $\mu \mathrm{K}$ temperature change, caused by that sudden change in $\mathbf{R}_{2}$, occurred in about $5 \mathrm{~s}$-thereafter a slowly changing drift (theoretically) remained (the behavior would closely resemble that shown in fig. 14 in [5]). Therefore (as a result of adjusting the drift balancer) the effects of the temperature perturbations in the thermistors were essentially non-existent, $<0.001 \%$ of the temperature rise caused by irradiation.

\section{Results}

Figure 9 shows a plot of the measured absorbed dose rates in polystyrene as a function of accumulated absorbed dose. The measurements were made over a 42-day period (the water was drained from the calorimeter after each day of measurement). The measurements were corrected for cobalt-60 decay to the first day of measurement. Each data point

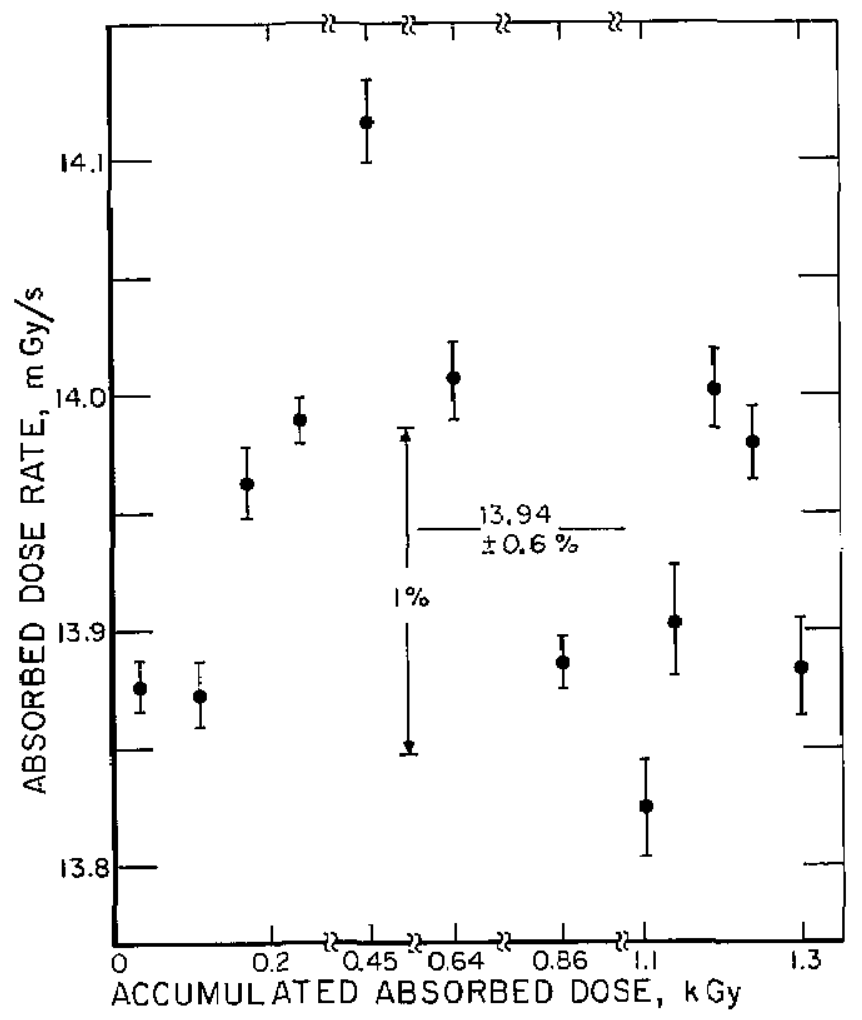

Figure 9-Plot of average results (with mean errors) of daily measurements of polystyrene absorbed dose rate as a function of accumulated absorbed dose. The standard deviation of the shown points is $0.6 \%$, 
represents an average result of 30 to 63 runs (each 90 to $120 \mathrm{~s}$ of irradiation), which resulted in an accumulated absorbed dose of 40 to $79 \mathrm{~Gy}$ for each group of runs. Each data point is shown plotted against the total absorbed dose the detector receivedthe sum it received on previous days plus the average it received on the day of measurement. The breaks shown in the abscissa indicate from 150 to $200 \mathrm{~Gy}$ of continuously delivered but unmeasured absorbed dose. The total absorbed dose was $1.33 \mathrm{kGy}$.

The individual runs (not shown) were plotted in all the groups. They showed increases or decreases, of questionable significance, with accumulated dose. The extremes of the changes varied from about a $1.5 \%$ increase on the first day to about a $2 \%$ decrease on another day. The detector received no irradiation prior to the first day of measurement. The $1.5 \%$ increase on the first day occurred up to an accumulated dose of about (30-40) Gy where a plateau was reached. The plateau extended to an accumulated dose of $70 \mathrm{~Gy}$, at the end of the first day of measurement.

There was no consistent evidence of significant effects on measurements of absorbed dose when, on 3 days, measurements were made with six different dissipations of thermistor electrical power $\left(P_{C}\right.$ and $\left.P_{f}\right)$ that ranged from 4.5 to $320 \mu \mathrm{W} .^{7}$ Measurements in the $C$-mode $\left(P_{C}=9 \mu \mathrm{W}\right.$ while $P_{J}$ was 0 , 9, or $\left.160 \mu \mathrm{W}\right)$ gave the same result as measurements in the J-mode $\left(P_{J}=9 \mu W\right.$ while $P_{C}$ was 0,9 , or $160 \mu W$ ).

Because there appeared to be no effect due to the various measurement conditions described, and even though the data on some days showed small variations, all the shown plotted data indicate an average of all measurements on a particular day. The uncertainties shown in figure 9 are standard errors of the mean that varied from 0.08 to $0.18 \%$. The computed standard deviation of each group of rans ranged from 0.5 to $1.0 \%$ with an average of $0.7 \%$. The plotted results shown in figure 9 were assumed to be random fluctuations about a constant value (no evidence of a continuous and significant change in

\footnotetext{
${ }^{7}$ This contrasts with a nearly $4 \%$ change in the measured absorbed dose in the water calorimeter when powers were changed from 9 to $200 \mu \mathrm{W}$ (fig. 13 in [5]). Also, even at the $320 \mu \mathrm{W}$ presently used, no change in response was noted as a result of small changes in room air pressure-previously observed. Perhaps the speculative reasons given there (in section 18 in [5D were correct, concerning the existing conditions and suggested changes (applied to the present detector) of the thermistor and lead embedments described in section 4 of the present paper. Further investigations will be made.
}

heat defect). An equal weight was assigned for the average result of each group. Averaging the 12 groups gives $13.94 \mathrm{mGy} / \mathrm{s}$ with a standard error of the mean of $0.17 \%$. The 12 average daily values (shown by the points) give a standard deviation of $0.6 \%$. Different averages of nine daily groups of measurements made with the water calorimeter give a standard deviation of $0.2 \%$ (fig. 20 in [5]) for the average daily reproducibility.

\section{Absorbed Dose to Water}

The absorbed dose rate in polystyrene, $\dot{D}_{\mathrm{p}}$, produced by gamma rays from a cobalt- 60 source, is converted to absorbed dose rate in water, $\dot{D}_{w}$, by evaluating the equation [22]:

$$
\dot{D}_{\mathrm{w}}=\frac{\left(\bar{\mu}_{\mathrm{en}} / \rho\right)_{\mathrm{w}}}{\left(\bar{\mu}_{\mathrm{en}} / \rho\right)_{\mathrm{p}}} \cdot P_{\mathrm{rep} 1} \cdot \dot{D}_{\mathrm{p}} .
$$

The first term is the ratio of the weighted mean, mass energy-absorption coefficients in water to that of polystyrene (weighted with the photon energy fluence) and the second term $\left(P_{\text {repl }}\right)$ is the replacement factor, to be discussed later.

Table 2 shows values used in determining the first term. Column 1 shows the energy intervals and column 2 shows values of the photon fluence per primary photon at a depth of $5 \mathrm{~g} / \mathrm{cm}^{2}$ [23]. The scattered fluence is shown to be $45 \%$ of the primary fluence. Column 3 shows values of the energy per primary photon, which has a mean energy of 1.252 MeV. The total scattered energy is shown to be 0.22 $\mathrm{MeV}$, which is $15 \%$ of the total radiation energy at the point of measurement. Columns 4 and 5 show values of the mass energy-absorption coefficients for water and polystyrene, respectively. Their ratios are shown in column 6 . Column 7 shows ratios of the mass attenuation coefficients of water to polystyrene. Values of all the coefficients were obtained from [24]. The last column shows values (in percent) of the scattered photon energy contributions to the total absorbed dose in polystyrene. The scattered energy contributes $16 \%$ to the measured absorbed dose.

The first term in eq (7) is

$$
\frac{\left(\bar{\mu}_{e n} / \rho\right)_{w}}{\left(\bar{\mu}_{\mathrm{en}} / \rho\right)_{p}}=\frac{Z_{w}}{Z_{\mathrm{p}}}=1.033
$$

where $Z=\bar{E}_{\text {pri }}\left(\mu_{\mathrm{en}} / \rho\right)_{\text {pri }}+\Sigma \bar{E}_{\text {scat }}\left(\mu_{\mathrm{en}} / \rho\right)_{\text {scart }}$. Respectively, $\bar{E}_{\mathrm{pri}}$ and $\vec{E}_{\mathrm{scat}}$ are the mean energies of the primary photon and of the scattered photons for the intervals shown in column 1 . The contribution of the scattered radiation to absorbed dose shown in column 8 is 
Table 2. Scattered radiation contributions to absorbed dose at $5 \mathrm{~g} / \mathrm{cm}^{2}$ depth

\begin{tabular}{|c|c|c|c|c|c|c|c|}
\hline $\begin{array}{l}\text { Photon } \\
\text { energy } \\
(\mathrm{MeV})\end{array}$ & $\begin{array}{c}\text { Fluence } \\
\text { per primary } \\
\text { photon } \\
(\times 100)\end{array}$ & $\begin{array}{c}\text { Energy } \\
\text { per primary } \\
\text { photon } \\
(\times 100) \\
(\mathrm{Mev})\end{array}$ & $\begin{array}{l}\left(\mu_{\mathrm{en}} / \rho\right)_{\mathrm{w}} \\
(\times 100) \\
\left(\mathrm{cm}^{2} / \mathrm{g}\right)\end{array}$ & $\begin{array}{l}\left(\mu_{\mathrm{en}} / \rho\right)_{\mathrm{p}} \\
(\times 100) \\
\left(\mathrm{cm}^{2} / \mathrm{g}\right)\end{array}$ & $\frac{\left(\mu_{\mathrm{en}} / \rho\right)_{\mathrm{w}}}{\left(\mu_{\mathrm{en}} / \rho\right)_{\mathrm{p}}}$ & $\frac{(\mu / \rho)_{w}}{(\mu / \rho)_{p}}$ & $\begin{array}{l}\text { Contribution to } \\
\text { total absorbed } \\
\text { dose in } \\
\text { polystyrene } \\
(\%)\end{array}$ \\
\hline & Scatter & Scatter & & & & & \\
\hline $0.00-0.10$ & 5.8 & 0.29 & 4.155 & 2.387 & 1.741 & 1.141 & 0.2 \\
\hline $0.10-0.20$ & 8.2 & 1.23 & 2.762 & 2.631 & 1.050 & 1.039 & 0.8 \\
\hline $0.20-0.30$ & 7.4 & 1.85 & 3.079 & 2.9 .72 & 1.036 & 1.036 & 1.3 \\
\hline $0.30-0.40$ & 1.6 & 0.56 & 3.236 & 3.131 & 1.034 & 1.034 & 0.4 \\
\hline $0.40-0.50$ & 2.2 & 0.99 & 3.289 & 3.185 & 1.033 & 1.033 & 0.7 \\
\hline $0.50-0.60$ & 2.0 & 1.10 & 3.292 & 3.188 & 1.032 & 1.033 & 0.8 \\
\hline $0.60-0.70$ & 2.6 & 1.69 & 3.264 & 3.162 & 1.032 & 1.033 & 1.3 \\
\hline $0.70-0.80$ & 2.4 & 1.80 & 3.225 & 3.125 & 1.032 & 1.033 & 1.3 \\
\hline $0.80-0.90$ & 2.5 & 2.13 & 3.179 & 3.081 & 1.032 & 1.033 & 1.5 \\
\hline $0.90-1.00$ & 2.8 & 2.66 & 3.126 & 3.030 & 1.032 & 1.033 & 1.9 \\
\hline $1.00-1.10$ & 2.6 & 2.73 & 3.072 & 2.978 & 1.032 & 1.033 & 1.9 \\
\hline $1.10-1.20$ & 3.0 & 3.45 & 3.017 & 2.925 & 1.032 & 1.033 & 2.4 \\
\hline \multirow[t]{3}{*}{$1.20-1.25$} & 1.4 & 1.72 & 2.976 & 2.885 & 1.032 & 1.033 & 1.2 \\
\hline & $\overline{45}$ & $\overline{22}$ & & & & & $\overline{16}$ \\
\hline & Primary & Primary &. & & & & \\
\hline $1.252^{\mathrm{a}}$ & 100 & 125.2 & 2.961 & 2.871 & 1.031 & 1.033 & 84 \\
\hline $0-1.252$ & $\begin{array}{c}\text { Total } \\
145\end{array}$ & $\begin{array}{c}\text { Total } \\
147\end{array}$ & & & & & 100 \\
\hline
\end{tabular}

This is the average primary photon energy.

$$
\bar{E}_{\text {scatt }}\left(\mu_{\mathrm{en}} / \rho\right)_{\text {scatt }} / Z,
$$

where this is evaluated for polystyrene.

The replacement factor, $P_{\text {repl }}$, was calculated as the ratio of the photon energy fluence in an all-water compared to a polystyrene-water calorimeter (at the position of measurement). The difference in photon energy fluence is caused mainly by the front disc, 10 $\mathrm{mm}$ thick. A simplified calculation gives

$$
P_{\text {repl }}=\mathrm{e}^{\left(\mu_{\mathrm{p}}-\mu_{\mathrm{w}}\right) \mathrm{k}},
$$

where $\mu_{w}$ and $\mu_{\mathrm{p}}$ are the linear attenuation coefficients (of the average primary photon energy) in water and polystyrene, and $t$ is the thickness of the polystyrene disc. This fraction calculates to be

$$
P_{\text {repl }}=1.001 \text {. }
$$

A detailed calculation, that includes the scattered spectrum, causes a difference of $<0.01 \%$. These calculated results give

$$
D_{\mathrm{w}}=1.034 D_{\mathrm{p}}
$$

This result is insensitive to the shape of the spectrum. The ratio of the $\mu / \rho$ values (column 7) is nearly independent of photon energy above approximately $0.1 \mathrm{MeV}$. The ratio values near unity would result in approximately the same spectrum in the two materials, including in a graphite medium to which the values listed in columns 1 and 2 actually apply ([23], columns 1 and 6 in table 1). The spectrum would vary slowly as a function of depth.

Below $0.1 \mathrm{MeV}$ the listed values in the first row show that although the ratios of coefficients increase sharply, the energy fluence is decreasing at a faster rate. These resulted in the indicated small contribution of $0.2 \%$ of the total (primary plus secondary) absorbed dose.

\section{Comparison of Calorimeter Results}

A comparison of absorbed dose rates to water, determined with three types of calorimeters, is given in table 3. The corrected and final results with the polystyrene-water, graphite, and water calorimeters are shown in the first row. The second row shows standard errors of the mean, in percent. The third row shows comparisons relative to the result determined with the calorimeter constructed of graphite which is known (as for polystyrene) to have an essentially zero heat defect. The result with the graphite calorimeter is 
Table 3. Calorimetric determination of absorbed dose to water

\begin{tabular}{lccc}
\hline & \multicolumn{3}{c}{ Calorimeter Type } \\
\cline { 2 - 5 } & $\begin{array}{c}\text { Polystyrene- } \\
\text { water }\end{array}$ & $\begin{array}{c}\text { Graphite } \\
{[6,7]}\end{array}$ & $\begin{array}{c}\text { Water } \\
{[5]}\end{array}$ \\
\hline Water dose rate (mGy/s) & 17.85 & 17.76 & 18.38 \\
Standard error of the mean $(\%)$ & 0.2 & 0.05 & 0.1 \\
Relative dose rate & 1.005 & 1 & 1.035 \\
Combined uncertainty (\%) & 1.1 & 0.6 & 0.4 \\
\hline
\end{tabular}

in agreement with the result determined with the polystyrene-water calorimeter, within the combined uncertainties shown in the last row. The above results are, however, in disagreement with the results determined with the water calorimeter. These results indicate an exothermic effect of $3-4 \%$ in irradiated water.

Measurements in copies of the NBS water calorimeter irradiated with cobalt 60 gamma rays are about $4 \%$ higher when compared with those determined with ionization chambers $[8,9]$.

\section{Corrections and Uncertainties}

Corrections and uncertainties in measurements of source-detector distance and detector depth near 5 $\mathrm{g} / \mathrm{cm}^{2}$ were negligible because of the optical sighting and micrometer measurements that were used. To compare with the water calorimeter results (that was slightly corrected to apply to an exact $5 \mathrm{~g} / \mathrm{cm}^{2}$ detector depth), the present result was decreased by $0.11 \%$ to correct to an equivalent electrons-per-unitarea detector depth. Effects of uncertainties in the calibrated temperature probe $(1 \mathrm{mK}$ temperature resolution), needed to measure the sensitivities of the thermistors, were negligible. A negIigible uncertainty was also assigned to the measurement of the sensitivities of the thermistors, because of the repeatability of the results shown in table 1 . To compare the present result with those determined with the water and graphite calorimeters, a correction was made for cobalt 60 decay by using a half. Jife value of $5.272 \pm 0.002$ years [25]. The correction factor was near 1.24, with negligible uncertainty. Čerenkov radiation contains wavelengths which are not locally absorbed but are readily transmitted in transparent materials like polystyrene and water. The maximum effect occurs for electrons from about 1-2 MeV. However, even in this range the effect is less than $0.1 \%$ of the electron energy loss by combined other effects. Therefore, the effect of Čerenkov radiation can be neglected, regardless of the incident radiation.
Table 4. Uncertainties in absorbed dose rate to water

\begin{tabular}{|c|c|c|}
\hline \multirow[b]{2}{*}{ Source } & \multicolumn{2}{|c|}{ Estimated uncertainty (\%) } \\
\hline & $\begin{array}{l}\text { Random } \\
\text { (degrees of } \\
\text { freedom) } \\
s_{i}\left(v_{j}\right)\end{array}$ & Other \\
\hline $\begin{array}{l}\text { Reproducibility of measurement groups } \\
\text { (fig. 9) }\end{array}$ & $0.2(11)$ & \\
\hline Heat defect & & 0.7 \\
\hline \multicolumn{3}{|l|}{ Dose-rate conversion, polystyrene to water } \\
\hline Absorption coefficient ratio $[24]$ & & 0.3 \\
\hline Low.energy photons & & 0.5 \\
\hline Specific heat capacity of polystyrene & & 0.5 \\
\hline Effect of lead resistances & & 0.05 \\
\hline Beam attenuation of calorimeter lid & $0.05(5)$ & \\
\hline Beam exposure timing & & 0.05 \\
\hline
\end{tabular}

Combined uncertainty $=\sqrt{\Sigma \mathrm{s}_{\mathrm{i}}^{2}+\overline{\Sigma \mu_{\mathrm{j}}^{2}}}=1.1 \%$.

Table 4 lists uncertainties from sources shown in column 1. The second column lists uncertainties $s_{\mathrm{i}}$ in terms of standard deviations of random measurements, and the numbers in parentheses are the corresponding numbers of degrees of freedom. The first listed source of uncertainty is $0.2 \%$, which is the standard error of the mean for the reproducibility of measurements on different days (from fig. 9). Ionization measurements in a water phantom showed that the aluminum foil and expanded polystyrene of the calorimeter lid decreased the measurements by $0.34 \%$. This correction was made and a $0.05 \%$ uncertainty was assigned.

Column 3 lists uncertainties $\mu_{\mathrm{j}}$ which are believed to be reasonable estimates of other uncertainties, to be treated as if they are standard deviations. Because of the essentially zero heat defect reported for different particles ([3], p. 14), $[12,13]$ and because there is only borderline evidence of a small endothermic heat defect $(0.67 \% \pm 0.97 \%$ [14]), no correction was applied but a $0.7 \%$ uncertainty was assigned. A $0.3 \%$ uncertainty was assigned in the energy-absorption coefficient ratios [24]. Although it was shown that the conversion factor (1.034) for converting absorbed dose in polystyrene to water is insensitive to the radiation spectrum, a $0.5 \%$ uncertainty was assigned in the event that the spectrum (particularly of low-energy photons) was greatly different from that used in the calculations. A $0.5 \%$ uncertainty is assigned for the specific heat capacity of polystyrene. The Pt-Ir leads fused to each thermistor bead had an average calculated resistance of $12 \mathrm{ohms}$, and the additional copper leads raised the resistance to an average of 27 ohms external to the nominal $3 \mathrm{k} \Omega$ resistance within the beads. The wires and thermistors have, 
respectively, a positive and negative temperature coefficient of resistance. A calculation showed that the results of measurements had to be increased by $0.98 \%$ because of the $27 \mathrm{ohm}$ external resistance-and increased further by $0.07 \%$ because that resistance increased slightly during irradiation. A $0.05 \%$ uncertainty was assigned. A $0.05 \%$ uncertainty was assigned to the beam exposure timing.

The combined uncertainty was calculated by using a recently recommended procedure [26]. That uncertainty was obtained by combining in quadrature the uncertainties shown in table 3 . The result is $1.1 \%$. Treating the combined uncertainty as if it were a mean error and multiplying it by 2 gives an overall uncertainty of $2.2 \%$.

\section{Further Investigations}

Some other thermal effects were investigated in the calorimeter both as described and in modified form. When the calorimeter was irradiated with cobalt-60 gamma rays, the $10-\mathrm{mm}$ thick discs were sufficient to stop the most energetic electrons emanating from the water. The electron spectrum at the sensors, therefore, was that emanating from polystyrene. From the surface to a depth of about $5 \mathrm{~mm}$ the electron spectrum is only slightly changed because of the difference in properties of the two materials. The effect is negligible, based on an approximate thermal diffusion calculation.

Similar effects at higher beam energies can be kept negligible by an easily made modification of securing additional dises to the detector assembly. This is shown in figure 10. Modification (a) shows the detector sandwiched by any necessary array of polystyrene discs separated by narrow gaps. This arrangement reduces the contributions of scattered radiation from the water. It also permits water to be made to flow between the gaps during agitation. Placement or removal of the discs would have little or no effect on the thermistor response shown in figure 5; but the solid-bodied calorimeter (b), with the same external dimensions and detector depth, would require a considerably longer time for the temperature gradients to subside [15]. Also, drift-producing temperature profiles (particularly those caused by successive runs with collimated beams of electrons) can be relatively easily erased in calorimeter (a); but in calorimeter (b) the time required for comparable equilibration would be prohibitively long (an unregulated surrounding temperature would result in delayed and oscillating drifts).

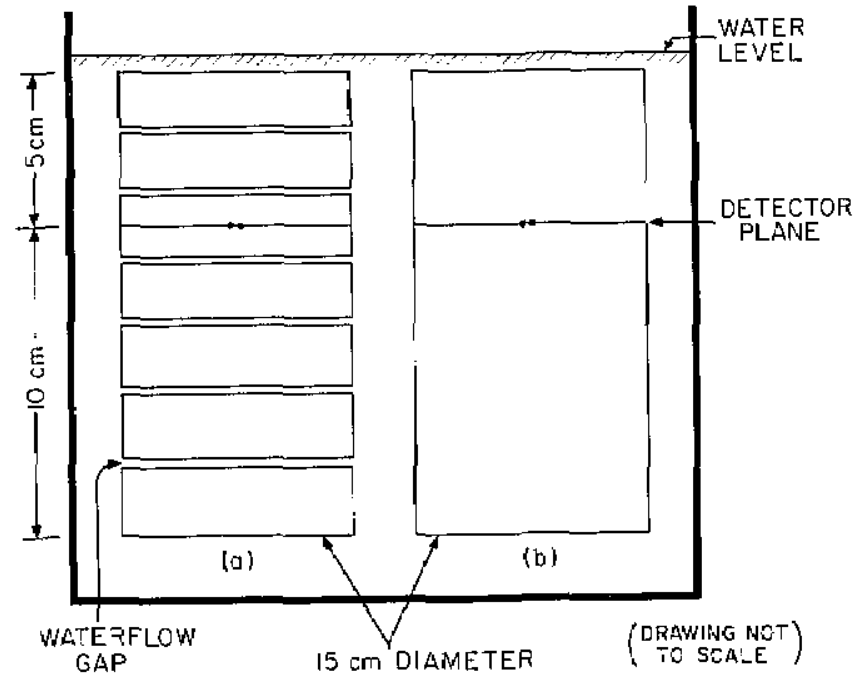

Figure 10-Illustrative modification designs of the polystyrene-water calorimeter.

It is interesting to compare the theoretically calculated changes in drift rates-along the axis at the $5 \mathrm{~cm}$ depth, from the top of the uppermost surface to the detector plane (of each calorimeter). It is also convenient to present temperature drift rates as equivalent absorbed dose rates, which is a more meaningful quantity to the operator.

Consider that the entire system (shown in fig. 10) is uniform in temperature. The water is agitated and suddenly raised in temperature by $1 \mathrm{~K}$. Figure 11 shows the changes in drift rates as a function of time.

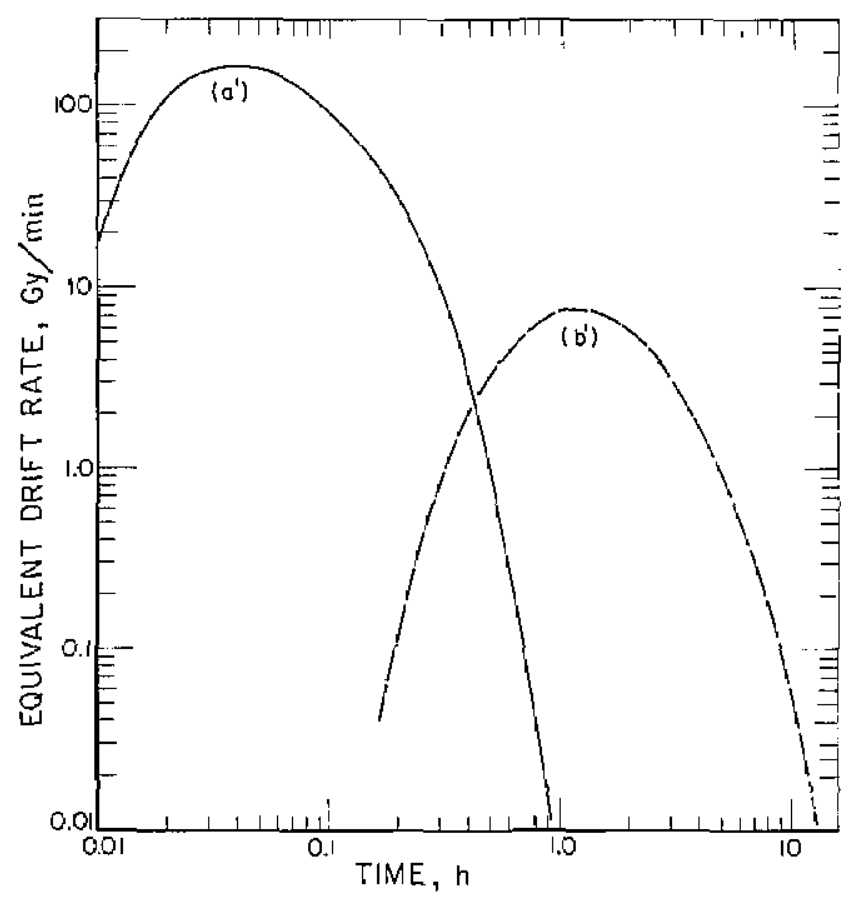

Figure 11-Calculated drift rates caused by thermal diffusion. 
Curves (a') and (b') show, respectively, the drift behaviors of calorimeters (a) and (b). Curve (a') indicates that within 1 hour the drift rates would be low enough, $<0.01 \mathrm{~Gy} / \mathrm{min}$, for calorimeter (a) to operate-verifying what was experienced. In contrast, curve (b') indicates that calorimeter (b) would have large and prolonged drift rates, $1-8 \mathrm{~Gy} / \mathrm{min}$ from $0.3-5 \mathrm{~h}$.

Section 9 describes the reduction of relatively small but still troublesome internal temperature drifts (in the calcrimeter in stag-lant water, shown in fig. 1), by use of the immersed electrodes to heat the entire water bath. The use of those electrodes may be ineffective with calorimeter (a). However, effectiveness can be achieved by connecting the electrode leads to other leads that extend into the two gaps adjacent to the detector (along diameters). Varying the eleotrical power dissipated in those water gaps will change the temperature gradients and will result in a reduction and control of observed temperature drifts. Such a system of heating sections of water for conductive plastic material) is deseribed in [27].

\section{Summary}

As with the water [5] and graphite [6] calorimeters, the polystyrene-water calorimeter proved that it can be placed quickly into operation. The mobility of the agitated water quickly brings the calorimeter close to a uniform operating temperature. Remaining temperature drifts were decreased and balanced mainly by use of an RC-circuit placed across a Wheatstone bridge. The charging potential was adjusted in such a manner that the changing electrical signal produced across the bridge was in a direction opposite to that produced by temperature gradients in the calorimete: Reduction of arge interna: : =mperabure gradisnts is important to reaucing drifls. Methous for reduction are dessrioed.

Posicioning the empty calorimeter, filling it with water to an acsurate depth, getting it into operation, and making 30 runs of $100 \mathrm{~s}$ curation for each irradiation required about 4 hours. A cobalt-60 absorbed dose rate near $14 \mathrm{mGy} / \mathrm{s}$ was measured with an uncertainty of about $0.7 \%$ standard deviation during a daily set of measurements. Comparison of daily sets of measurements in polystyrene indicated no consistent evidence of a change in beat defect. The accumulated absorbed dose was $1.33 \mathrm{kGy}$.

The result with the presently described polystyrenewater calorimeter agrees to $0.5 \%$ vith a result previously determined with a graphite calorimeter (graphite, as for polystyrene, is known to have an essentially zero heat defect). A previous result determined with a water calorimeter is higher by $3-4 \%$, indicating this magnitude of an exothermic effect in water irradiated wth cobalt-60 gamma rays.

The study described is part of a second phase of a previously mentioned investigation: the investigation of irradiation effects produced by different beams, absorbed dose rates, and accumulated absorbed dose that may calse significant positive or negative heat defects at a point of measurement-particularly izi water which is the standard reference material [3]. The polystyrene-water calorimeter now provides an efficient investigative tool for comparison of the calorimeters under widely different irradiation concitions-conditions where ic is uncertain if evidence of an essentjally zero heat defect will still exist in polystyrene. To aid in alleviating this concern, and to provide other comparative investigative took, plans are to design and investigate an A.150 plasticwater and a graphite-water calorimeter. Different models of this general latter design are described in [28] and [29].

In general, the techniques described in this paper can be applied to any material-water calorimeter, to compare the beat defects of those materials for potential calorimetric use, such as a recently developed "solid water" plastic material [30]. Comparison of figure 1 in the present paper with figure 3 in [5] shows that the only differences are the detectors (that are readily interchangeable) and the different roles played by the shown immersed electrodes. The interchangeability provides a convenient feature for comparison of absorbed dose measurements in different materials by making use of a single calorimetric structure and the same measuring equipment. Elimination of a vacuum system, often used with absorbed dose calorimeters. further adds to the simaicily of tise basie repotec tesign.

\section{References}

[1] Domen, S. R, A polystyrene-water calorimeter. Int. J. Appl. Raciat. Isot. 34(3): 643-544; 1983 March.

[2] Domen, S. R. A ersperatore-drift belancer for calcrime-:y. Ir.1. J. Appl. Radict. Isoc. 34(6): 927-92x; 1933 June.

[3] ICRU Rep. No. 14, Radiation dosimetry: $X$ rays and gamma rays with maximum photon energies between 0.6 and 50 MeV. Appendix B, ICRU Publications, Washington, DC, 1969.

[4] Domen, S. R. Absorbed dose water calorimeter. Med. Phy's. 7(2): 157-159; 1980 March-April.

[5] Domen, S. R. An absorbed dose water calorimeter: Theory, design, and performance, J. Res. Natl. Bur. Stand. (U.S.) 87(3): 211-235; 1982 May-June. 
[6] Domen, S. R.; Lamperti, P. J. A heat-loss-compensated calorimeter: Theory, design, and performance. J. Res. Natl. Bur. Stand. (U.S.) 78A(5): 595-610; 1974 September-October.

[7] Pruitt, J. S.; Domen, S. R.; Loevinger, R. The graphite calorimeter as a standard of absorbed dose for cobalt 60 gamma radiation. J. Res. Natl. Bur. Stand. (U.S.) 86(5): 495-502; 1981 September-October.

[8] Marles, A. Comparison of measurements of absorbed dose to water using a water calorimeter and ionization chambers for clinical radiotherapy photon and electron beams. Ph.D. Thesis (1981), Univ, of Texas (Houston).

[9] Kubo, H. Absorbed dose determination with a water calorimeter in comparison with an ionisation chamber. Phys. Med. Biol. (in press).

[10] Boyd, A. W. Private communication, 1981.

[11] Fletcher, J. W. Radiation chemistry of water at low dose rates with emphasis on the energy balance; a computer study. AEC $\vec{L}-7834$ (Chalk River Nuclear Laboratories, Ontario, Canada); 1982.

[12] Weimer, G. Energiedosisabhängigkeit des kalorischen defekts in kunststoffen. Atomkernenergie 20(4): 327-328; 1972.

[13] Weimer, G. Kalorimetrische dosimetrie schneller neutronen unter berücksichtigung des kalorischen defekts. Dissertation. Giessen: 1. Physikalisches Institut der Universität; 1973.

[14] Säbel, M.; Schmidt, Th.; Pauly, H. Heat defect of low energy $x$-rays in some materials of interest in absorbed dose calorimetry. Rad. and Environm. Biophys. 11: 259-264; 1974.

[15] Zeitz, L.; Laughlin, J. S. "Nonisolated-sensor" solid polystyrene absorbed dose measurements. Med. Phys. 9(5): 763-768; 1982 September-October.

[16] Gaur, U.; Wunderlich, B. Heat capacity and other thermodynamic properties of linear macromolecules. $\mathrm{V}$. Polystyrene. J. Phys. Chem. Ref. Data, 11(2): 313-325; 1982.

[17] Smathers, J. B.; et al. Composition of A-150 tissue-equivalent plastic. Med. Phys. 4(1): 74-77; 1977 January-February.

[18] McDonald, J. C.; Goodman, L. J. Measurements of the thermal defect for A-150 plastic. Phys. Med. Biol. 27(2): 229-333; 1982 February.

[19] Olson, F. C. W; Schultz, O. T. Temperatures in solids during heating or cooling. Ind. Eng. Chem. 34(7): 874-877; 1942 July.

[20] Ingersoll, L. R.; Zobel, O. J.; Ingersoll, A. C. Heat conduction. Madison, WI, The University of Wisconsin Press, 299-300 (1954).

[21] Ho, C. Y.; et al. Thermophysical properties of polystyrene and poly (vinyl chloride). Cezairliyan, A., ed. Proceedings of the seventh symposium on thermophysical properties; 1977 May 10-12; Gaithersburg, MD (ASME); 198-218.

[22] Loevinger, R. A formalism for calculation of absorbed dose to a medium from photon and electron beams. Med. Phys. 8(1): 1-12; 1981 January-February.

[23] Comite consultatif pour les etalons de mesure des rayonnements ionisants, Section I-Rayons $\mathbf{x}$ et $\gamma$, electrons; $2^{\mathrm{c}}$ Reunion, 1972 May 3-5, Sevres, France, BIPM.

[24] Hubbell, J. H. Photon mass attenuation and energy-absorption coefficients from $1 \mathrm{keV}$ to $20 \mathrm{MeV}$. Int. J. Appl. Radiat. Isot. 33: 1269-1290; 1982 November.

[25] Hanson, H. H.; Legrand, J. Cobalt.60 decay. At. Energy Rev. 11: $576-641 ; 1973$.

[26] Kaarls, R. Report of the BIPM Working Group on the statement of uncertainties. 1980.

[27] Domen, S. R. Absorbed dose water calorimeter. U.S. Patent Number 4,312,224; 1982 January.

[28] Hohlfeld, K.; Reich, H. Calibration of dose meters in terms of absorbed dose in water for ${ }^{60} \mathrm{Co} \gamma$-radiation. Proceedings of an International Symposium on National and International Standardization of Radiation Dosimetry; 1977 December 5-9; Atlanta, GA, Vol. 2: 81-89.

[29] Sundara Rao, I. S.; Naik, S. B. Graphite calorimeter in water phantom and calibration of ionization chambers in dose to water for ${ }^{60} \mathrm{Co}$ gamma radiation. Med. Phys. 7(3): 196-201; 1980 May-June.

[30] Constantinou, C.; Attix, F. H.; Paliwal, B. R. A solid water phantom material for radiotherapy $x$-ray and $\gamma$-ray beam calibrations. Med. Phys. 9(3): 436-441; 1982 May-June. 